\title{
ASPECTOS DA DIMENSÃO \\ DISCURSIVA DA MEMÓRIA \\ NOSTÁLGICA: UMA ANÁLISE \\ DE EDITORIAIS DA \\ REVISTA FERROVIA ${ }^{1}$
}

\section{ASPECTOS DE LA DIMENSIÓN DISCURSIVA DE LA MEMORIA NOSTÁLGICA: UN ANÁLISIS DE EDITORIALES DE LA REVISTA FERROVIA}

\author{
ASPECTS OF THE DISCURSIVE DIMENSION OF NOSTALGIC MEMORY: AN ANALYSIS OF \\ REVISTA FERROVIA EDITORIALS
}

Alana Destri*

Anselmo Lima ${ }^{* *+}$

Universidade Tecnológica Federal do Paraná

RESUMO: O presente artigo focou-se no estudo da manifestação da nostalgia no discurso e na delimitação de aspectos subjetivos desta enquanto fenômeno sígnico e ideológico. O estudo discursivo desse fenômeno, pelo viés teórico do Círculo de Bakhtin, firmase no fato de que a nostalgia, universal e contundente, não pode ser compartilhada e tampouco vivida se não através de signos e, consequentemente, de enunciados. Para tanto, fez-se uso de um corpus de pesquisa notoriamente nostálgico que conta com 106 editoriais da Revista Ferrovia publicados entre 1935 e 2017. Dentre todos, três tiveram sua análise em detalhe a fim de ressaltar o

\footnotetext{
${ }^{1}$ Uma versão preliminar deste artigo foi apresentada no VII CÍRCULO - Rodas de Conversa Bakhtiniana (2018).

Mestra em Letras pelo Programa de Pós-Graduação em Letras da Universidade Tecnológica Federal do Paraná (UTFPR).E-mail: alanadestri@outlook.com. 
vínculo do enunciado nostálgico com o tempo histórico em que se vive. A síntese disto gera um poderoso efeito catártico que se perpetua nas esferas da atividade humana como instrumento para suportar um presente de agruras.

PALAVRAS-CHAVE: Memória nostálgica. Signo ideológico. Sociedade.

RESUMEN: El presente artículo se centró en el estudio de la manifestación de la nostalgia en el discurso y en la delimitación de aspectos subjetivos de la misma como fenómeno sígnico e ideológico. El estudio discursivo de este fenómeno, desde el punto de vista teórico del Círculo de Bakhtin, se afianza en el hecho de que la nostalgia, universal y contundente, no puede ser compartida y tampoco vivida si no lo es a través de signos y, consecuentemente, de enunciados. Para estos fines, se hizo uso de un corpus de investigación notoriamente nostálgico que cuenta con 106 editoriales de la Revista Ferrovia publicados entre 1935 y 2017. De entre todos, tres tuvieron su análisis en detalle a fin de resaltar el vínculo del enunciado nostálgico con el tiempo histórico en que se vive. La síntesis de esto genera un poderoso efecto catártico que se perpetúa en las esferas de la actividad humana como instrumento para soportar un presente de penurias/amarguras.

PALABRAS CLAVE: Memoria nostálgica. Signo ideológico. Sociedad.

ABSTRACT: The present work focused on the study of nostalgia manifestation in the discourse and on the delimitation of subjective aspects of it as a sign and an ideological phenomenon. The discursive study, by Bakhtin's Circle theory, establishes itself in the fact that nostalgia, universal and meaningful, cannot be shared nor lived but through signs and, consequently, utterances. In order to develop this research, a noticeable nostalgic corpus was used: 106 editorials of Revista Ferrovia published between 1935 and 2017. Among all of them, three had their analysis in detail in order to emphasize the link of nostalgic utterance and historical time in which the enunciator lives. The synthesis of this generates a powerful cathartic effect that perpetuates itself in the spheres of human activity as an instrument to bear a present of hardship.

KEYWORDS: Nostalgic memory. Ideological sign. Society.

\section{INTRODUÇÃO}

Nostalgia está em voga. Design vintage, fotos instantâneas estilo Polaroid, retomada de grandes franquias, remakes de filmes do século passado. O mercado faz crescentemente uso do conjunto estético do passado, pois - evidentemente - vende. Em um momento pós-moderno de mudanças constantes, e por vezes caóticas, o passado mostra-se fonte de estabilidade, um oásis em meio a um grande terreno de areias movediças. Nostalgia é uma solução: talvez fantasiosa, mas com efeito claro e contundente na individualidade e no social. Naturalmente, nostalgia vende porque é comprada - no mais amplo sentido da palavra.

Um notável exemplo de manifestação linguístico-discursiva da nostalgia enquanto reflexo político-social pode ser observado no Saudosismo português. O sentimento, em caráter nacionalista, inundou de tal forma a vida lusófona que saudade passou a ser tida como traço típico da nação. Como reflexo, observa-se a mesma característica nas produções literárias no início do século XX, perpetuando-se historicamente como movimento literário. Hoje, de forma global, experimenta-se um terreno cada vez mais fértil para a rememoração nostálgica. Portanto, é de se esperar que a nostalgia permeie de forma crescente os discursos nas mais diversas esferas da comunicação humana - não apenas na literatura. Compreender este fenômeno e, sobretudo, saber identificar como se é exposto a ele, é uma forte ferramenta de autoconhecimento que viabiliza os caminhos para a concepção de quem se é em meio a sociedade em que se vive.

Justificado seu valor como tema de pesquisa, ressalta-se que o presente texto compõe a dissertação apresentada em 2018 ao Programa de Pós-Graduação em Letras da Universidade Tecnológica Federal do Paraná (UTFPR), sob o título de "Aspectos da dimensão linguístico-discursiva da memória nostálgica: uma análise de editoriais da Revista Ferrovia." Este recorte em específico tem como objetivo aprofundar-se sobre a manifestação da nostalgia no discurso e traçar aspectos subjetivos da mesma enquanto fenômeno sígnico e ideológico. 
Para tanto, fez-se uso de um corpus de pesquisa que conta com 106 editoriais da Revista Ferrovia publicados entre 1935 e 2017 e, aqui, enfocam-se três edições: 2, 62 e 172. A Revista Ferrovia foi e continua a ser veiculada pela Associação dos Engenheiros da Estrada de Ferro Santos-Jundiaí - AEEFSJ com a finalidade de promover discussões e divulgar matérias sobre a ferrovia. É direcionada a leitores que atuam na comunidade ferroviária, governantes, bem como integrantes de empresas públicas e privadas. Este corpus foi selecionado para o estudo sobre nostalgia, pois a classe ferroviária, coletivo responsável pela revista, admite-se nostálgica e imprime de forma marcante a nostalgia em seu discurso. Rememora-se com frequência a já ida era dourada da ferrovia, na qual tal sistema funicular possuía o monopólio dos transportes no Brasil. Monopólio este que fora frustrado, entre outras coisas, por interesse e influência estadunidense sobre investimentos na malha rodoviária brasileira (MATOS, 1990).

Tendo isso em vista, o conceito de nostalgia e os conhecimentos a ela atrelados foram majoritariamente baseados nos estudos de Constantine Sedikides et al (2008), os de memória e sociedade no de Ecléa Bosi (2003) e os de retrotopia no de Zygmunt Bauman (2017). No campo da Linguística e Socioideologia, a pesquisa apresenta de forma central embasamento teórico em Mikhail Bakhtin (2016), e Valentin Volóshinov (2017). De Vygotsky (1999), aproveita-se o conceito da catarse e, por fim, representando a esfera do desenvolvimento humano, têm-se Anselmo Lima (2015) com o conceito de atividade reguladora.

Os apresentados arcabouços teóricos foram mobilizados, então, para que as análises fossem possíveis. Estas foram feitas buscando compreender como as informações obtidas articulam-se a ponto de formar um todo significativo com relação à manifestação do fenômeno da nostalgia no discurso e possíveis desdobramentos.

\section{SIGNO IDEOLÓGICO, MEMÓRIA E SOCIEDADE}

Nostalgia é anseio por algo do passado. O anseio pode ser por determinados eventos, pessoas, perspectivas. Além disso, nostalgia é uma experiência universal que se manifesta durante toda a duração da vida, independentemente da idade, gênero, classe social ou etnia (SEDIKIDES; WILDSHUT; BADEN, 2004). É, inclusive, um sentimento que estreita os laços sociais. Um grupo que partilha de uma mesma rememoração nostálgica acaba por se sentir mais amado e protegido, com níveis menores de ansiedade e evasão, reportando possuir uma melhor competência interpessoal. A nostalgia, de forma individual ou compartilhada, auxilia a construção do sentido da vida, o que ajuda a pessoa a lidar com os conflitos existenciais do presente (SEDIKIDES et al., 2008). Nesta nova mentalidade contemporânea, vale muito mais investir em retornar a um passado nebuloso, mas valoroso por sua suposta estabilidade e confiabilidade, do que nutrir esperanças em políticas de melhoria que guiariam o mundo para um futuro incerto. $\mathrm{O}$ futuro é mirado entre expectativa de fracasso e medo (BAUMAN, 2017).

Logo, é uma constante certas classes produzirem memória coletiva que "[...] se alimenta de imagens, sentimentos, ideias e valores que dão identidade àquela classe” (BOSI, 2003, p. 18). Segundo a autora, quando há a construção social da memória dentro de um determinado grupo, este tem "[...] a tendência de criar esquemas coerentes de narração e interpretação dos fatos, verdadeiros 'universos de discurso', 'universos de significado', que dão ao material de base uma forma histórica própria, uma versão consagrada dos acontecimentos" (BOSI, 1994, p. 27). Ao fazer isso, os indivíduos fazem uso da ideologia, estereótipos e mitos para construir e fixar a própria imagem para a história. Deste modo, não há a memória "pura" de um fato, mas sim, uma memória complexa e permeada de ideologia. Assim é possível, no trabalho de pesquisa nesta área, reconstruir os comportamentos e sensibilidades de uma época se o pesquisador estiver atento ao subentendido, ao implícito dos discursos (BOSI, 2003).

Os discursos em situação real de comunicação são compostos de enunciados individuais, únicos e irrepetíveis. Isso pois reflete a individualidade do enunciador, seu estilo próprio de compor os enunciados. Junto disso, é único e irrepetível, pois o tratamento temático dado ao objeto nunca será dado de mesma forma, mesmo em situações idênticas de comunicação social (VOLÓCHINOV, 2017).

Os enunciados, por sua vez, são compostos de signos linguísticos. Para Volóchinov, o signo é ideológico, ou seja, é uma realidade que remete a outra realidade. Neste processo, o signo como realidade material reflete e refrata uma realidade que vai além dele (VOLÓCHINOV, 2017). A ideologia está em todos os campos da sociedade e cada campo interpreta e significa a realidade de forma 
distinta. No entanto, seja via símbolos, leis, peças artísticas etc, todos os fenômenos ideológicos têm em comum o caráter sígnico. Isso porque a compreensão de um signo só se faz em relação ao outro e esse processo de compreensão ideológica é ininterrupto e baseado na interação social. É social mesmo na qualidade de signo interior porque a consciência individual só passa a existir quando se tem inserido nela material ideológico, signos. E, concomitantemente, o signo só se desenvolve no processo de interação entre, pelo menos, dois indivíduos socialmente organizados (VOLÓCHINOV, 2017).

Tendo em vista a onipresença do signo em toda e qualquer esfera da comunicação social, é de se esperar que a palavra seja o signo que mais sensivelmente transpareça às mudanças sociais. A palavra é um indicador dessas mudanças, pois é nela que se acumulam pouco a pouco as mudanças que podem vir a se tornar um novo produto ideológico. Para a compreensão desses signos, Volóchinov reitera que a psicologia social não deve ser vista como algo interior. Deve ser conceituada como uma troca material de palavras, gestos, ações que permeiam exteriormente as relações interpessoais (VOLÓCHINOV, 2017).

Com isso, formado por signos, o enunciado é conceituado como elo ou correia: "[o]s enunciados e seus tipos [...] são correias na transmissão entre história da sociedade e a história da linguagem" (BAKHTIN, 2016). Ou seja, eles refletem em si as mudanças da sociedade e "[c]ada enunciado é um elo na corrente complexamente organizada de outros enunciados" (BAKHTIN, 2016). Em situação real de comunicação, os enunciados se repetem e se recriam em uma cadeia ininterrupta, considerando os enunciados anteriores e prevendo os posteriores (BAKHTIN, 2016).

Às formas relativamente estáveis de enunciado Bakhtin dá o nome de gêneros do discurso. Os gêneros discursivos são constituídos por quatro elementos coesos e inseparáveis, são eles: conteúdo temático, estilo, estrutura composicional e relação interlocutiva (BAKHTIN, 2016). O conteúdo temático centra-se principalmente nos sentidos que se constroem em interações dialógicas entre indivíduos sobre determinado objeto de discurso. Logo, o enunciado está sempre endereçado a alguém, tendo um objetivo específico (SOBRAL, 2009). Com o estilo há a avaliação e adaptação dos modos de enunciar devido ao processo de modificação individual dado ao gênero para melhor se adequar à situação real de enunciação. A estrutura composicional, por sua vez, trata-se de todo o material gramatical e de convenção ligado à estrutura do gênero. Por fim, a relação interlocutiva está intimamente ligada à situação do enunciador e modifica-se frente àquele com quem se dialoga. Leva-se em consideração a relação social específica entre os sujeitos em diálogo, a percepção que um tem do outro, a relação de ambos com a temática do enunciado etc. Naturalmente, tal relação modifica-se de acordo com objeto sobre o qual se enuncia. (SOBRAL, 2009).

De acordo com isso, Lima (2015) discorre sobre o desenvolvimento da afetividade, emoções e sentimentos humanos. Lima explicita que a atividade do ser humano per se é fonte inesgotável de contradições. De forma contínua, o indivíduo busca significar estas contradições e oscila entre dois pontos diametralmente opostos. Neste fenômeno, cunhado pelo autor como atividade reguladora (LIMA, 2015), o ser oscila em sua atividade até que, devido a repetições em circunstâncias relativamente estáveis, a oscilação passa a diminuir de amplitude até chegar em um ponto de amplitude mínima no qual acontece um "curto-circuito". Com isso, ambas as formas de atividade combinam-se e originam uma terceira, diferente das duas anteriores. Ao chegar a este ponto, o indivíduo experimenta o efeito catártico, efeito este responsável pela liberação de energia psíquica acumulada, algo prazeroso de se ter (LIMA, 2015). Com isso, por meio da atividade reguladora, o indivíduo busca ir além de si mesmo, crescer em competência - seja ela qual for.

Vygotsky também disserta a respeito do efeito catártico sobre o social e o biológico do ser humano - mas através da arte. O sentimento, para o autor, é descarga de energia psíquica viva, reação orgânica geral em resposta a um afeto. No caso da apreciação de uma obra de arte, a descarga é tão maior quanto a comoção que ela promove. A base operacional do sentimento cotidiano e do provocado pela arte é a mesma, no entanto, diferenciam-se no que se refere à manifestação externa e intensidade do elemento fantasioso. É na unidade de sentimento e fantasia que se baseia a arte. Por ser a fantasia momento central da reação emocional da peça artística, quando se sente a partir desta a emoção, o sentimento processa-se no córtex cerebral e, muito comumente, não deflagra ação a partir disto, diferentemente do sentimento cotidiano (VYGOTSKY, 1999).

Na arte, as emoções provocadas pela temática, pelo conteúdo, estão sempre em antagonismo com as emoções provocadas pela forma com a qual estão dispostas. Com isso, em suma, Vygotsky (1999, p. 270) afirma que "a lei da reação estética é uma só: encerra em si

Destri \& Lima Aspectos da dimensão discursiva da memória nostálgica: uma análise de editoriais da revista Ferrovia 
a emoção que se desenvolve em dois sentidos opostos e encontra a destruição no ponto culminante, como uma espécie de um curtocircuito". Isto se relaciona com a atual pesquisa porque a nostalgia não só é um sentimento, mas também porque liga-se diretamente ao catártico. Ademais, tanto a catarse provinda da nostalgia quanto a provinda de uma reação estética qualquer está intrinsecamente ligada com as demais reações do ser humano. A vida encontra-se, assim, na arte.

\section{DESENVOLVIMENTO}

A partir dos conceitos basilares discorridos anteriormente, compreende-se que a comunicação não ocorre no vazio, por meio de um estéril código linguístico. Toda interação dialógica reflete e refrata o momento social e histórico no qual o se produziu. O enunciado é único e irrepetível e assim também são os enunciados-corpus nostálgicos desta pesquisa. Todos foram estudados, cada um é elo em uma corrente complexa de outros enunciados, continuamente respondendo a enunciados anteriores e prevendo posteriores. Desta forma, pode ser observado que tanto os editoriais quanto a nostalgia sentida pelos ferroviários se repete e se recria ao longo dos anos.

Para evidenciar, portanto, o caráter vivo da manifestação da nostalgia e sua contundência no contexto do coletivo social e no desenvolvimento humano deste, esta sessão comenta e relaciona três editoriais nostálgicos da Revista Ferrovia. Escolheu-se, portanto, o primeiro editorial nostálgico de todos: “Uma das causas do deficit[sic] nas ferrovias”, de 1967, número 2, escrito por José Sartoris Netto (Anexo A); o editorial que se localiza no meio da linha do tempo de editoriais, "Hierarquia", de 1978, número 62, escrito por José Ferreira (Anexo B); e, por fim, o último dos editoriais nostálgicos do corpus, "Palavra da Presidente”, 2017, número 172, escrito por Maria Lina Benini (Anexo C).

Déficit. O editorial número 2 inicia uma longa tradição de editoriais com esta palavra como conteúdo temático central. Assim como 32\% dos editoriais (DESTRI, 2018), este traz a adversidade à tona. Netto retrata o momento histórico em que a ferrovia já se encontra em segundo plano em relação ao monopólio dos transportes do Brasil. A ferrovia de Netto é uma ferrovia já deficitária, que cada vez perde mais espaço para as rodovias. Sendo assim, o autor nostalgicamente lembra dos tempos dourados, mas afirma que os tempos mudaram e que a mentalidade e hierarquia dentro do sistema deveria se adequar. A grande questão, segundo ele, é a diminuição da procura de frete e uma administração que não dá a importância que este serviço merece. $\mathrm{O}$ editorialista inicia o editorial ativando o leitor mnemonicamente, sensibilizando-o:

\footnotetext{
Vivem saudosos em nossa memória <<0s bons tempos >> do monopólio dos transportes ferroviários em nosso país. Naquêles[sic] tempos, por não existirem as boas rodovias e serem precários de conforto e capacidade de carga dos veículos, as ferrovias eram procuradas e até imploradas para a obtenção de uma passagem ou vagão para o despacho de mercadorias [...] (FERREIRA, 1978, p. 5).
}

Enquanto destaca os bons tempos, contrasta em mesma medida o presente - claramente diferente, quase irreconhecível. Utiliza a primeira pessoa do plural, como a maioria dos editoriais, a fim de se colocar no mesmo grupo social que o leitor, mostrar que compartilha da mesma situação difícil que ele. Em contraste com o padrão da relação interlocutiva dos editoriais - a relação ferroviário/ferroviário - por tratar de problemas que poderiam ser amenizados pelo alto escalão de engenheiros, o autor assume a posição de engenheiro para conversar com outros engenheiros, ou seja, a relação interlocutiva deste editorial centra-se na relação engenheiro/engenheiro. Mais à frente no texto, a nostalgia continua:

E as mercadorias para serem transportadas?

Ah! estas. $<<$ nos bons tempos $>>$, estavam a cargo dos clientes das ferrovias que as procuravam para $<<$ conseguir $>>0$ seu transporte.

Porém os tempos foram mudando [...]. Hoje, nas ferrovias, vivemos ainda a mesma mentalidade e aquela mesma hierarquia, porém em outros tempos (FERREIRA, 1978, p. 5).

Há a repetição do contraste claro entre "os bons tempos" e os "outros tempos”, os tempos que "foram mudando". O autor suspira em palavras ao anteceder sua descrição do passado com a expressão “Ah!”. A mudança claramente não foi boa e o passado é 
lembrado com carinho. Ao final do texto o futuro é trazido, reivindicando a "redenção do sistema ferroviário". Evocando a teoria de Benveniste, o tempo crônico é "[...] o tempo dos acontecimentos, que engloba também nossa própria vida enquanto sequência de acontecimentos" (BENVENISTE, 2016, p.71). Nesta perspectiva, o tempo é a sucessão de grupos de acontecimentos amarrados em pontos de referência em uma escala convencionada conhecida por todos. Logo, no corpus, o tempo crônico é apresentado compreendido como uma sequência de fatos que não favoreceram a classe ferroviária.

Cada indivíduo é um observador do tempo crônico no que tange à possibilidade de percorrer essa linha de acontecimentos ocorridos do presente para o passado e do passado para o presente. No entanto, "[...] é pela língua que se manifesta a experiência humana do tempo" (BENVENISTE, 2016, p. 74). É onde o editorialista tem a total liberdade de transitar indiscriminadamente entre passado e futuro. Sendo assim, o tempo linguístico se define e se organiza em função do discurso. O centro da linha temporal é gerado no momento da enunciação e novos centros são gerados a cada resposta dada ou a cada novo editorial. Este, ao definir o hoje de 1967 como "outros tempos", transita em uma linha de ida e volta para o passado dos "bons tempos" mais de uma vez. Ao enunciar, e só por que enunciou, o editorialista viveu verdadeiramente o seu passado de novo. Há um passeio pela história coletiva: a nostalgia aparente no primeiro parágrafo se desfaz com a descrição do presente, retorna no corpo de texto e está inclusive no apelo final para que haja alguma tomada de decisão referente à fretagem.

No momento da enunciação desse enunciado, os ferroviários já parecem ter deixado a ideia utópica de retomar o monopólio do transporte. Em editoriais prontamente seguintes, é evidente que o que desejam no momento é voltar a trabalhar em uma classe que não é maltratada, que não opera com orçamento curto e políticas deficitárias. Em regra, desistiram até mesmo de um futuro sem déficit - mas conclamam um futuro em que o déficit não seja visto como prejuízo, mas, sim, investimento. No presente em que vivem, querem o melhor para si - algo que se opõe ao melhor para a indústria rodoviária. Vê-se aqui, portanto, claramente a valoração dada pelos ferroviários para a ferrovia em detrimento da valoração dada por outros setores a ela.

Sessenta editoriais depois, tem-se o texto que segmenta em duas partes o corpus de editoriais nostálgicos. Este, inclusive, é o último editorial nostálgico antes da busca pela "modernização" da revista, a qual alterou a formatação do texto de retangular para triangular. "Hierarquia" de José Ferreira tem o conteúdo temático de mudança estrutural. Versa sobre o espírito de simplificação de cargos que tem sido adotado pela empresa e em como essa manobra administrativa parece ser falha quando perdem-se as hierarquias na hora das decisões que levarão a empresa para o futuro. Observe-se:

É preciso que o PCC que foi criado com tanto esforço e boas intenções, continue se modificando, (como aliás foi a intenção de seus criadores), com a arte e a criatividade que sabemos que não faltará aos ferroviários, procurando-se um caminho onde se possa estabelecer para as nossas ferrovias "Escala Hierárquica", condizente com os dias "cibernéticos" de hoje, mas que cumpra também as funções de "Escala Hierárquica" dos anos de ouro da Ferrovia (NETTO, 1967, p. 5).

Ele fala na primeira pessoa do plural ao utilizar "nossas ferrovias", o que atrai para si a posição de engenheiro perante o leitor que provavelmente também é ferroviário, mas que, sobretudo, compartilha da posição de engenheiro. Inclusive, utiliza a abreviação PCC sem introduzi-la, tomando como garantida a compreensão dessa palavra em um coletivo que partilha de uma mesma esfera semântica que o autor. Tal atitude solidifica o tom social dessa comunicação até então trimestral como uma ferramenta de sobrevivência do grupo. Dizer que a ferrovia teve seus anos dourados é confirmar a ideia de que ela tem legitimidade em requerer e conseguir o prestígio novamente. Neste processo, citando Bosi (2003), o indivíduo renova-se para o presente, recebe forças para continuar. Neste caso, a memória é decisiva na existência do indivíduo ferroviário e de seu coletivo pois permite fazer a relação do nós do presente com o nós do passado e, concomitantemente, interfere no curso das significações da esfera ferroviária.

O centro da linha temporal está "nos dias 'cibernéticos' de hoje" e ele transita para um passado anterior ao da segunda publicação. Ou seja, por mais que 1967 seja passado no momento desta enunciação, o ponto no passado para o qual ambos voltam é o mesmo: "os bons tempos", "os tempos de ouro da Ferrovia". Desta vez a nostalgia fora posicionada no final do discurso a fim de solidificar seus argumentos apresentados e motivar o leitor.

Destri \& Lima Aspectos da dimensão discursiva da memória nostálgica: uma análise de editoriais da revista Ferrovia 
O terceiro editorial comentado é o último número publicado e, também, é o último do corpus de editoriais nostálgicos. O de número 172 tem caráter profundamente nostálgico e é detentor de quase todos os padrões de manifestação nostálgica encontrados em análise completa do corpus (DESTRI, 2018).

Este número é o quinto após um período de hiato entre 2010 a 2015. Em comemoração aos oitenta anos de publicação, a revista retorna apresentando um editorial voltado para os conteúdos da revista, não tão argumentativo quanto os anteriores. Mesmo assim, a editorialista não deixa de transparecer a nostalgia própria e coletiva do setor ferroviário. A revista, publicada em ano comemorativo de 150 anos da primeira estrada de ferro paulista - São Paulo Railway - é repleta de conteúdo saudoso, festeja seu passado histórico. Assim também é o editorial: rememora a criação, o desenvolvimento e a infeliz queda da ferrovia brasileira. Comenta o presente de 2017 instaurando-o como centro axiológico do enunciado e termina com um olhar positivo sobre o futuro. Para retratar seu conteúdo nostálgico, tem-se o trecho a seguir:

\begin{abstract}
A "Ingleza" - ou também "SPR" - se destacou também por ser a estrada férrea mais rentável do Brasil, da América Latina e de todas as outras abaixo da linha do Equador [...] um verdadeiro contraste com o atual cenário ferroviário brasileiro, depois de erradicada boa parte das linhas férreas existentes à época da edição histórica da revista. Se os tempos encantados da tração a vapor e das máquinas fixas do maior sistema funicular construído no mundo são hoje nostalgia, nada apaga a realidade que seus quase $140 \mathrm{~km}$ de trilhos catapultaram São Paulo à condição de estado mais desenvolvido da nação e, portanto, nada tão apropriado como chamá-lo de "Locomotiva do Brasil". (BENINI, 2017, p. 3)
\end{abstract}

A valoração do autor aos objetos do discurso - o passado e o presente - é nítida como em todos os demais editoriais com manifestação de nostalgia. O passado é sempre apresentado de forma positiva: "rentável", "tempos encantados", "Locomotiva do Brasil". Em contrapartida, o atual cenário é apresentado em contraste: a ferrovia não é mais rentável, os tempos não são mais encantados, ela não participa em peso do progresso brasileiro.

Outros padrões gerais de editoriais nostálgicos que podem ser observados neste editorial é que, assim como 55\% dos demais discursos, o elemento nostalgia é colocado ao final com função de motivar o leitor ferroviário na luta pela melhoria da esfera. Ademais, a relação interlocutiva gerada foi a de ferroviário/ferroviário assim como $47 \%$ dos editoriais.

Benini, como editorialista e presidente, coloca-se como membro de um coletivo ferroviário não-seleto, ou seja, não direciona o comentário para o grupo de ferroviários engenheiros ou de alta hierarquia. Mas sim, coloca-se simplesmente como ferroviária comunicando assim que a história de glória da ferrovia pertence a todos, sejam eles grandes engenheiros, maquinistas ou zeladores.

A rememoração nos coletivos e, neste caso, o ferroviário, é ferramenta primordial de manutenção da classe e a nostalgia corrobora na construção de sua identidade e motivações. Por outro lado, observa-se que o passado que Benini relata é um passado que ela não viveu. E por mais que tivesse vivido, as memórias são complexamente permeadas de ideologia (BOSI, 2003). E, observando o histórico de editoriais nostálgicos, quanto mais a situação se dificulta, quanto mais o passado parece longínquo, mais a memória nostálgica se fortalece e, com as diversas retomadas mnemônicas, é passível de ser modificada bioquimicamente no cérebro. Isso porque as memórias obedecem às alterações moleculares sinápticas. E, tratando de forma sucinta, a evocação é modulada por neurotransmissores entre as sinapses, de acordo com os fatores emocionais do ser no momento da rememoração (IZQUIERDO et al., 2013).

Não se emociona com a nostalgia apenas aquele que sente a perda de deslocamento. A nostalgia é também, de forma profunda, um romance do nostálgico com sua própria fantasia do passado. Sendo assim, tal romance só consegue sobreviver em uma relação de longa distância, pois quando se tenta sobrepor a fantasia nostálgica atual com o passado realmente ocorrido não há correspondência exata (BOYM, 2007). Trocam-se presidentes, mudam-se os colegas, morrem-se os veteranos. Quando não há mais ninguém que viveu em tempo físico o passado crônico que tanto rememoram linguisticamente, a memória não morre. A nostalgia permanece como componente, como traço característico do coletivo. Como Bauman reitera (2017), o presente incerto da virada do século não inspira confiança. Vale muito mais investir no olhar para um passado certo do que apostar na instabilidade do futuro. 
Vale mais porque a nostalgia é catártica. A atividade reguladora de LIMA (2015) está inclusive no fato de as pessoas rememorarem nostalgicamente. Aqui o indivíduo oscila entre viver no passado - algo impossível - e viver no presente - algo insuportável. O curtocircuito se dá no meio termo entre os dois elementos: a nostalgia. A síntese está no viver no presente buscando motivação no passado. Neste ponto ela é responsável pelo efeito catártico, prazeroso de se rememorar.

A nostalgia como fonte de catarse observa-se não só nos editoriais, mas na própria ato de publicação do periódico. Na primeira edição de 1935 não se sentia o gosto amargo do déficit que fez o coletivo retomar a revista em 1967 - revista essa que renasceu nostálgica. Publicar foi uma resposta ao afeto do fracasso empresarial, uma forma de manipular um instrumento que pudesse ajudálos a ir além deles mesmos, a superar os desafios que o presente apresentava.

Em sua estrutura, memória nostálgica também goza de um embate dicotômico que se finda em catarse. A memória como conteúdo é superada pela narrativa semi-biográfica. Ou seja, a narrativa contada para si mesmo, ao se rememorar, não representa o objeto da nostalgia como tal - é parte verdade, parte criação. O resultado é um prazer catártico semelhante ao artístico: a destruição do conteúdo pela forma.

\section{CONSIDERAÇÕES FINAIS}

O objetivo desta pesquisa foi aprofundar-se sobre a manifestação da nostalgia no discurso e traçar aspectos subjetivos desta enquanto fenômeno sígnico e ideológico. Para alcançá-lo, utilizou-se um corpus de editoriais nostálgicos da Revista Ferrovia, elencaram-se os conceitos necessários para o embasamento teórico, bem como investigou-se o contexto histórico e de produção dos editoriais. Juntamente a essas etapas da pesquisa, fez-se uma análise sobre os editoriais contidos nas edições número 2, 62 e 172. Tal análise desvelou o laço estreito entre a nostalgia e o tempo histórico em que é vivida. Permeado de ideologia, o fenômeno de rememorar nostalgicamente atinge todas as esferas de atividade humana e é cultivado, comunicado e perpetuado com traços característicos de cada classe.

Busca-se na nostalgia a experiência da fronteira nem sempre nítida do que era e do que é. Assim, foram analisados três editoriais distintos representando três momentos diferentes da história da ferrovia. Observou-se uma intensificação da nostalgia conforme o tempo se passava. A nostalgia foi evocada em resposta a afetos na existência do grupo social e, segundo Sedikides et al, esta é uma força humana fundamental, parte importante da vida cotidiana, que serve como promotora de positividade, autoestima, ligações sociais e alívio das agruras do existir (2008). Por ser parte memória e parte narrativa autoral, pode-se dizer que a manifestação da nostalgia se assemelha à função da arte. Por mais que tal sentimento possa influenciar a arte e o mercado, ela não é matéria em museus, não é selecionada ou analisada por críticos, não se classifica em barroca ou surrealista. No entanto, as memórias são degustadas nostalgicamente com o mesmo fervor com o qual se observa um grande quadro ou se aprecia uma boa narrativa. A nostalgia é ao mesmo tempo verdade e criação, um traço humano universal que culmina em um prazeroso efeito catártico.

Mas como alguém se entrega ao sentimento da nostalgia se este é em partes fantasia ou até mesmo delírio? O grande atrativo desse sentimento é, justamente, que a nostalgia não é de todo invenção e nem de todo factual. Além disso, a parte fantástica é dificilmente notada, visto que o passado não é acessível diretamente. Pode-se recordar a partir de vídeos, imagens, diários, mas indubitavelmente a forma mais comum de se recordar uma memória nostálgica é confiando apenas no armazenamento químico das próprias memórias.

Reforça-se aqui que a memória não é exatamente confiável, pois existe a crença de que "se gravam" memórias como qualquer sistema de armazenamento digital. A memória evanesce e, principalmente, altera-se. É comum que o nostálgico não tenha consciência do quão alterada pode estar aquela memória doce do passado. A memória alterada parece tão verdadeira na memória quanto a memória original, confundem-se as fronteiras. De qualquer forma, quando se há a necessidade de rememorar nostalgicamente frente ao presente caótico, o que se procura é estabilidade. É preferível acreditar que aquilo que lhe dá segurança não seja fruto de alterações químicas em sucessão. Na sociedade do "cada um por si" e do "posso apenas confiar em mim mesmo" não poder confiar

Destri \& Lima Aspectos da dimensão discursiva da memória nostálgica: uma análise de editoriais da revista Ferrovia 
nas próprias lembranças é assustador. E, como em um ciclo, para aliviar-se das agruras de um presente volúvel e buscar razões para continuar nele, busca-se novamente o colo quente, aconchegante e catártico da nostalgia.

\section{REFERÊNCIAS}

BAKHTIN, M. Os gêneros do discurso. In:_BAKHTIN, M. Os gêneros do discurso. Trad. Paulo Bezerra. São Paulo: Editora 34, 2016. P. 09-70.

BAUMAN, Z. Retrotopia. Trad. Renato Aguiar. Rio de Janeiro: Zahar, 2017.

BENINI, M. L. Palavra da presidente. [Editorial]. Revista Ferrovia, n. 172, p. 3, 2017.

BOSI, E. Memória e sociedade: lembranças de velhos. 3. ed. São Paulo, Companhia das

Letras, 1994.

BOSI, E. O tempo vivo da memória: ensaios de Psicologia Social. São Paulo: Ateliê Editorial, 2003.

BOYM, S. Nostalgia and its Discontents. Hedgehog Review, Charlottesville - EUA, University of Virginia, n. IX. p. 7-18, 2007.

DESTRI, A. Aspectos da dimensão linguístico-discursiva da memória nostálgica: uma análise de editoriais da Revista Ferrovia. 2018. Dissertação (Mestrado) - . Programa de Pós-graduação em Letras, Gerência de Ensino e Pesquisa, Universidade Tecnológica Federal do Paraná, 2018.

FERREIRA, J. Hierarquia. [Editorial]. Revista Ferrovia, n. 62, p. 5, 1978.

IZQUIERDO, I. et al. Memória: tipos e mecanismos - achados recentes. Revista USP, São Paulo, n. 98, p. 9-16, 28 ago. 2013. Disponível em: https://doi.org/10.11606/issn.2316-9036.v0i98p9-16. Acesso em: 31 maio 2019.

LIMA, A. Desenvolvimento da afetividade, das emoções e dos sentimentos humanos no (e fora do) trabalho: uma questão de saúde coletiva e segurança pública. Saúde Soc, São Paulo, v. 24, n. 3, p. 869-876, 2015. Disponível em: http://www.scielo.br/pdf/sausoc/v24n3/0104-1290-sausoc-24-03-00869.pdf. Acesso em: 31 maio 2019.

MATOS, O. N. de. Café e ferrovias: a evolução ferroviária de São Paulo e o desenvolvimento da cultura cafeeira. Campinas, SP: Pontes, 1990.

NETTO, J. S. Uma das causas do deficit nas ferrovias. [Editorial]. Revista Ferrovia, n.2, p.5, ago. 1967.

SEDIKIDES, C et al. Nostalgia: Past, Present, and Future. Current Directions in Psychological Science, Washington - EUA, vol. 7, n. 5, p. 304-307, $2008 . \quad$ Disponível em: http://www.wildschut.me/Tim Wildschut/home files/Sedikides, $\% 20$ Wildschut, $\% 20$ Arndt, $\% 20 \% 26 \% 20$ Routledge, $\% 202008, \% 20$ CDir.pdf. Acesso em: 13 ago. 2018. 
SEDIKIDES, C.; WILDSCHUT, T.; BADEN, D. Nostalgia: Conceptual Issues and Existential Functions. In: GREENBERG, J.; KOOLE, S. L.; PYSZCZYNSKI, T. A. (org.). Handbook of Experimental Existential Psychology. New York - EUA: Guilford Publications, 2004. p. 200-215. Disponível em: http://studylib.net/doc/8267824/nostalgia---university-of-southampton. Acesso em: 13 ago. 2018

SOBRAL, A. Do dialogismo ao gênero: as bases do pensamento do círculo de Bakhtin. Campinas, SP: Mercado de Letras, 2009.

VOLÓCHINOV, V. Marxismo e filosofia da linguagem: problemas fundamentais do método sociológico na ciência da linguagem. Trad. Sheila Grillo e Ekaterina Vólkova Américo. São Paulo: Editora 34, 2017.

VYGOTSKY, L. S. Psicologia da arte. Trad. Paulo Bezerra. São Paulo: Martins Fontes, 1999.

\section{(ㄷ) (1) $(\circledast$}


ANEXO A - "Uma das causas do deficit[sic] nas ferrovias", editorial da edição número 2, 1967.

COMENTARIO

\section{UMA DAS CAUSAS DO DEFICIT NAS FERROVIAS}

Vivem saudosos em nossa memória «os bons tempos» di monopóiio dos transportes ferroviários em nosso pais.

Naquêles tempos, por não existirem as boas rodovias \& serem precários o confôrto e capacidade de carga dos veículos as ferrovias eram procuradas e até imploradas para a obtenção de uma passagem ou vagão para o despacho de merca. dorias.

Esse ambiente gerou dentro delas uma mentalidaơe e um hierarquia na importância das funções dentro da emprêsa que as estão liquidando pelo processo chamado deficit.

Os administradores consomem tôdo o seu tempo em obras de melhoria das linhas férreas, sinalização, magnificas esta cỏes, lcomotivas, sempre reclamando maior número de vagões esquecendo-se de que estão à frente de uma emprêsa indus trial e de que ế importante à sua gerência a boa operaçāc da ferrovia, isto é, a circulação rápida de seus vagões. proporcionando maior rendimento e rentabilidade, e mais importante, ainda, o êxito comercial da emprêsa.

Quanto à hierarquia, continuam a prevalecer os homens que fazem a operação de transporte vindo em segundo planc os que tratam do êxito financeiro da emprêsa.

Mas, como dissemos, a estrada de ferro é uma emprêsá industrial que VENDE FRETE, como resultado do trars porte de passageiros e mercadorias.

$\mathbf{E}$ as mercadorias para serem transportadas?

Ah! estas. «nos bons tempos», estavam a cargo dos clientes das ferrovias que as procuravam para «conseguir» $c$ seu transporte.

Porém os tempos foram mudando, as boas rodovias ana. recendo, os veículos rodoviários melhorando o seu confôrtc e sua capacidade de carga e, assin, inicianóo violenta concorrência pela preferência do transporte.

Hoje, nas ferrovias, vivemos ainda a mesma mentalidade e aquela mesma hierarquia, porém em outros tempos.

Os clientes já não as procuram com a mesma frequência e necessidade e, enquanto os vagões ficam nos desvios ou correm vazios em retôrno, pululam nas rodovias, em itinerários paralelos, uma imensidade de caminhões. Vejase por exemplo as Vias Anhanguera, Dutra e Anchieta.

De que adianta uma via permanente perfeita, uma sinalização automática, locomotivas modernas, tudo isso somando custos de investimentos e manutencão fabulosos, se passageiros e cargas seguem via rodoviária?

Os administradores de nossas ferrovias, se fiserem um exame de consciência, certamente considerar-se-ão culpados de não imprimirem às emprêsas que dirigem, uma orientação em bases verdadeiramente comerciais.

Reunem-se com seus auxiliares para saber como gastar suas verbas, porém descuidam do mais importante, gue é como ganhar essas verbas.

Para a redenção do sistema ferroviário nacional devem os seus responsáveis encarar as estradas de ferro como emprêsas industriais cujo único produto a oferecer é $\rho_{\text {trans- }}$ porte e que os fretes sejam vendidos em livre concorrência, como uma mercadoria qualquer, num balcãa de ựa Ioja comercial.

JOSE SARTORIS NETTO

$$
+5-
$$


ANEXO B - "Hierarquia”, editorial da edição número 62, 1978.

\section{EDITORIAL}

\section{HIERARQUIA}

Eng: José Ferreira

A Ferrovia, mais ainda que a grande maioria das empresas, necessita para seu funcionamento perfeito de uma escala hierárquica, onde se possa definir comando e responsabilidade.

Tal fato se contradiz pelo menos aparentemente com espírito de simplificação de cargos, que adotado para racionalizar e facilitar as operações administrativas na área de pessoal e finanças, e aplicado visando sem dúvida os interesses da empresa.

Cria-se assim, um dilema, pois ambas as funçōes. (hierarquia e simplificaçāo), são do mais alto interesse da empresa e até agora nào nos parece que a melhor solução para o momento atual tenha sido encontrada.

Muitas funçōes da área operacional que foram englobadas carecem de reestudo visando uma hierarquização para que se possa concentrar algumas decisões que devem ser tomadas por presteza e com responsabilidade bem definida, pois envolvem algumas vezes segurança de tráfego e quantas e quantas vezes o próprio interesse final da empresa.

É preciso que o PCC que foi criado com tanto esforço e boas intenções, continue se modificando, (como aliás foi a intençāo de seus criadores), com a arte e criatividade que sabemos não faltará aos ferroviários, procurando-se um caminho onde se possa estabelecer para as nossas ferrovias uma "Escala Hierárquica", condizente com os dias "cibernéticos" de hoje, mas que cumpra também_as funções do "Escala Hierárquica" dos anos de ouro da Ferrovia. 


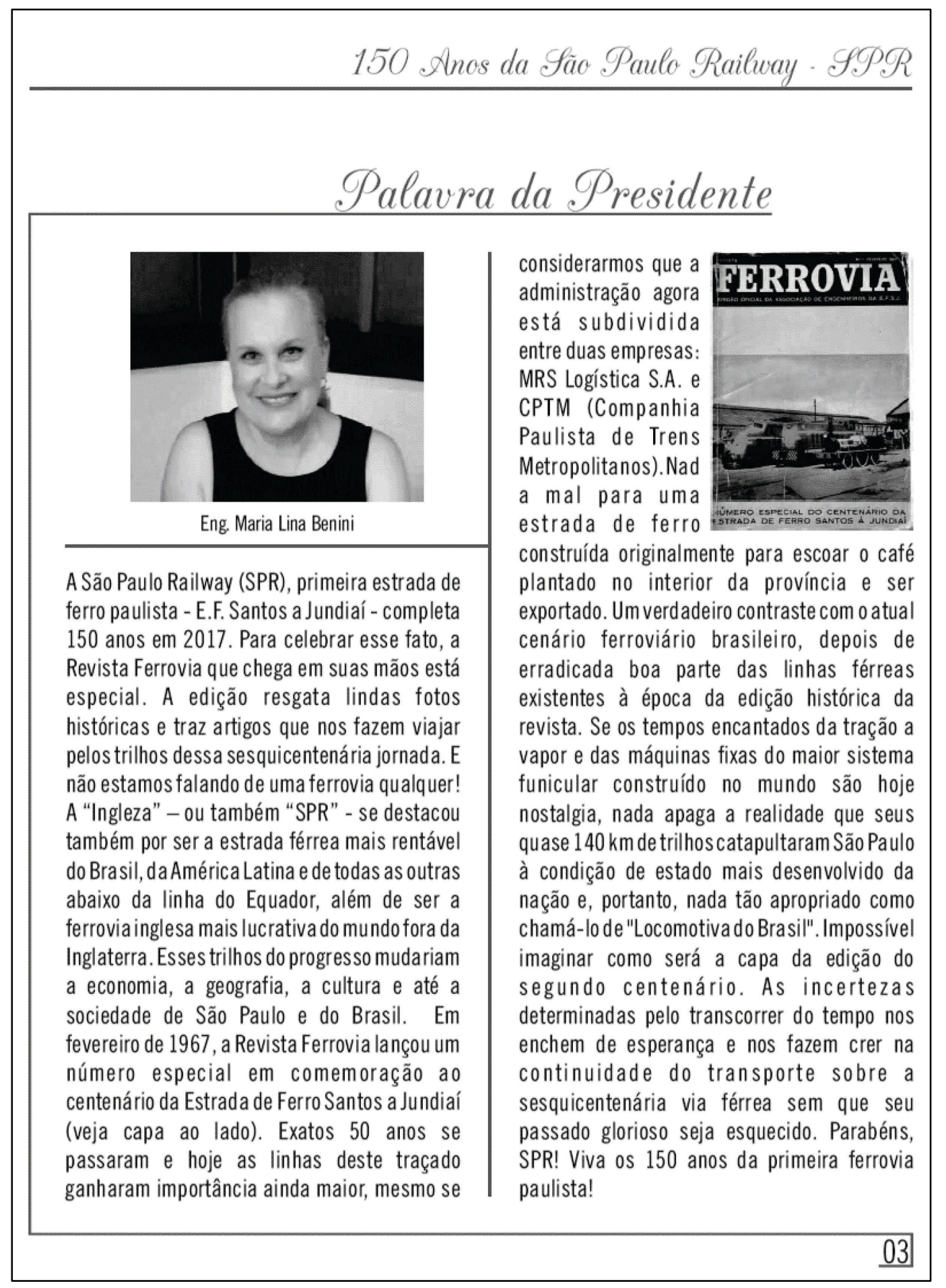

